\title{
Identification and quantification of cannabinol as a biomarker for local hemp retting in an ancient sedimentary record by HPTLC-ESI-MS
}

\author{
Theresa Schmidt ${ }^{1}$ - Annemarie Elisabeth Kramell ${ }^{1} \cdot$ Florian Oehler $^{2} \cdot$ Ralph Kluge $^{1} \cdot$ Dieter Demske $^{3}$. \\ Pavel E Tarasov ${ }^{3}$ - René Csuk ${ }^{1}$
}

Received: 28 November 2019 / Revised: 22 January 2020 / Accepted: 5 February 2020 / Published online: 14 February 2020

(C) The Author(s) 2020

\begin{abstract}
Cannabis products have been used in various fields of everyday life for many centuries, and applications in folk medicine and textile production have been well-known for many centuries. For traditional textile production, hemp fibers were extracted from the stems by water retting in stagnant or slow-moving waters. During this procedure, parts of the plant material, among them phytocannabinoids, are released into the water. Cannabinol $(\mathrm{CBN})$ is an important degradation product of the predominant phytocannabinoids found in Cannabis species. Thus, it is an excellent indicator for present as well as ancient hemp water retting. In this study, we developed and validated a simple and fast method for the determination of CBN in sediment samples using highperformance thin-layer chromatography (HPTLC) combined with electrospray ionization mass spectrometry (ESI-MS), thereby testing different extraction and cleanup procedures, as well as various sorbents and solvents for planar chromatography. This method shows a satisfactory overall analytical performance with an average recovery rate of $73 \%$. Our protocol enabled qualitative and quantitative analyses of CBN in samples of a bottom sediment core, having been obtained from a small lake in Northern India, where intense local retting of hemp was suggested in the past. The analyses showed a maximum CBN content in pollen zone 4 covering a depth range of 262-209 cm, dating from approximately 480 BCE to $1050 \mathrm{CE}$. These findings correlate with existing records of Cannabis-type pollen. Thus, the method we propose is a helpful tool to track ancient hemp retting activities.
\end{abstract}

Keywords HPTLC $\cdot$ Cannabinol $\cdot$ Sediment $\cdot$ Biomarker $\cdot$ Cannabis $\cdot$ Hemp retting

\section{Introduction}

Cannabis has been used by humans for many centuries and is probably one of the oldest cultivated plants [1]. It is widely distributed around the world, and archaeological finds indicate

Electronic supplementary material The online version of this article (https://doi.org/10.1007/s00216-020-02492-0) contains supplementary material, which is available to authorized users.

Annemarie Elisabeth Kramell

annemarie.kramell@chemie.uni-halle.de

1 Department of Organic Chemistry, Martin-Luther-University Halle-Wittenberg, Kurt-Mothes-Str. 2, 06120 Halle, Germany

2 Department of Inorganic Chemistry, Martin-Luther-University Halle-Wittenberg, Kurt-Mothes-Str. 2, 06120 Halle, Germany

3 Section Paleontology, Institute of Geological Sciences, Freie Universität Berlin, Malteserstr. 74-100, 12249 Berlin, Germany its usage for more than 2500 years. For instance, almost complete ancient Cannabis plants as well as parts of it have been excavated from different tombs in the Jiayi and Yanghai cemetery located in Northwestern China dating back to the first millennium BCE $[2,3]$. Cannabis is a versatile plant and has been used as medicine, food source (seeds and oil), fuel, and psychedelic drug and also as a construction material or for the production of textiles and paper. The production of hemp fibers, e.g., for the manufacturing of robes, requires the separation of the fibers from the stems through microbiological and physical processes occurring during retting. Traditionally, the extraction of the fibers from stems is performed in stagnant or slow-moving waters, thereby submerging the stems in water for several days. During this treatment plant material and among other substances, phytocannabinoids are released into the waters. Phytocannabinoids are unique to the Cannabis species. The predominant phytocannabinoids in drug- and fiber-type Cannabis are (-)- $\Delta^{9}$-trans-tetrahydrocannabinolic acid (THCA) and cannabidiolic acid (CBDA) that are 
transformed by a non-enzymatically decarboxylation upon heating after harvesting and during storage into their corresponding neutral forms, namely (-)- $\Delta^{9}$-trans-tetrahydrocannabinol $\left(\Delta^{9}-\mathrm{THC}\right)$ and cannabidiol (CBD). Phytocannabinoids accumulate in female flowers and in most aerial parts of the plant. In contrast, Cannabis pollen, seeds, and roots contain only low concentrations of these compounds [4]. The concentration of cannabinoids and the ratio $\Delta^{9}$-THC:CBD depend on different parameters such as growth conditions, variety, age, harvest time, and storage conditions $[4,5]$. Especially during storage, $\Delta^{9}$-THC is relatively unstable whenever Cannabis products such as flowering tops, oils, and resins are exposed to air, light, heat, or acidic conditions [6]. Eventually, cannabinol (CBN) is one of the most important products of degradation $[7,8]$. CBD also undergoes changes during long-term storage, e.g., the transformation to $\Delta^{9}$-THC by an acidcatalyzed cyclization, followed by the decay of $\Delta^{9}$-THC to CBN (Fig. 1) [8,9]. Therefore, it is not surprising that $\mathrm{CBN}$ has been detected as the major degradation product of cannabinoids in dried Cannabis flowers dating from around 1896-1905 [10]. Studies concerning the CBN content in sedimentary records, however, are rare. Thus, Lavrieux et al. reported about the detection of CBN, preserved in sediment samples from lake Aydat in the French Massif Central, covering the past 1800 years [11], thereby relating the presence of $\mathrm{CBN}$ to the retting of locally grown Cannabis plants for fiber production. This finding was supported by the analysis of pollen and historical data. Thus, determination of CBN contents in sedimentary cores seems to be an excellent possibility to trace ancient water retting activities.
Fig. 1 Conversion of CBDA and THCA to CBD and THC as well as the formation of the main degradation product CBN<smiles>C=C(C)[C@H]1CCC(C)=C[C@H]1c1c(O)cc(CCCCCC)c(C(=O)O)c1O</smiles>

CBDA<smiles>C=C(C)[C@H]1CCC(C)=C[C@H]1c1c(O)cc(CCCCCCCCCC(C)(C)C)cc1O</smiles><smiles>CCCCCCc1cc2c(c(O)c1C(=O)O)C1C=C(C)CC[C@@H]1C(C)(C)O2</smiles><smiles>CCCCCCc1cc(O)c2c(c1)OC(C)(C)[C@@H]1CCC(C)=C[C@H]21</smiles>

$\Delta^{9}-\mathrm{THC}$<smiles>CCCCCCc1cc(O)c2c(c1)OC(C)(C)c1ccc(C)cc1-2</smiles> 
In a previous study, sediment samples from lake Aydat were investigated, and the detection of $\mathrm{CBN}$ was performed by gas chromatography mass spectrometry (GC-MS). However, this approach required a time-consuming derivatization with $\mathrm{N}, \mathrm{O}$-bis(trimethylsilyl)trifluoroacetamide (BSTFA). In general, different methods, e.g., GC-MS, liquid chromatography tandem mass spectrometry (LC-MS/MS), or (high-performance) thin-layer chromatography MS ((HP)TLC-MS) technique, are available for the quantification of cannabinoids in various matrices such as human blood, plasma, hair, urine, rodent tissues, or plant material [12-14]. Here, HPTLC combined with MS detection is a versatile and useful tool for the analysis of complex compounds in challenging matrices, thus enabling a relatively simple, rapid, and inexpensive qualitative and quantitative determination. However, the application of HPTLC-MS for the determination of CBN in sediment samples, a very complex matrix, has not yet been described so far.

In this study, we report on the development and validation of a HPTLC-electrospray ionization (ESI)-MS method for the identification and quantification of CBN as a molecular biomarker for ancient hemp retting in sedimentary records allowing a fast and accurate high-throughput screening of sediment samples. In this context, samples of a sediment core from a small lake in Northern India, covering a period from $2220 \mathrm{BCE}$ to $1390 \mathrm{CE}$, were tested. Previous studies on these samples have already shown high percentages of Cannabis-type pollen, thus indicating an intense local retting of hemp [15].

\section{Material and methods}

\section{Chemicals and materials}

CBN (1 mg/mL in methanol, certified reference material), $\mathrm{CBN}_{-} \mathrm{d}_{3}(100 \mu \mathrm{g} / \mathrm{mL}$ in methanol, certified reference material), CBD (1 mg/mL in methanol, certified reference material), and CBD- $\mathrm{d}_{3}(100 \mu \mathrm{g} / \mathrm{mL}$ in methanol, certified reference material) were bought from Cerilliant; acetonitrile (HPLC gradient grade), methanol (HPLC gradient grade), $n$-hexane (HPLC grade), $n$-heptane (HPLC grade), and formic acid (98-100\%) were obtained from VWR Chemicals; dichloromethane (HPLC grade) from Carl Roth, triethylamine from ACROS Organics, Fast Blue Salt B (FBS, dye content $\sim 95 \%$ ) from Sigma-Aldrich, Chromabond $\mathrm{SiOH}(1 \mathrm{ml} / 100 \mathrm{mg})$, Chromabond $\mathrm{C}_{18}$ ec ( $1 \mathrm{ml} / 100 \mathrm{mg}$ ) as well as TLC (thin-layer chromatography) plates (silica gel 60, ALUGRAM Xtra SIL G UV 254 and octadecyl-modified silica, ALUGRAM $\mathrm{RP}-18 \mathrm{~W} / \mathrm{UV}_{254}$ ) from Macherey-Nagel, TLC plates (silica gel 60 without fluorescent indicator on aluminum sheets), and HPTLC (high-performance thin-layer chromatography) plates (silica gel $60 \mathrm{~F}_{254} \mathrm{MS}$-grade for matrix-assisted laser desorption/ionization (MALDI) and silica gel $60 \mathrm{~F}_{254}$ on glass plates) were purchased from Merck $\mathrm{KGaA}$ and analytical sea sand from Grüssig GmbH. Distilled diethyl ether and acetone were produced with a rotary evaporator from BÜCHI.

\section{Preparation of standard solutions}

A stock solution of CBN from Cerilliant $(1 \mathrm{mg} / \mathrm{mL}$ in methanol) was diluted with methanol to obtain working solutions down to a concentration of $0.3 \mu \mathrm{g} / \mathrm{mL}$. CBN- $\mathrm{d}_{3}$ working solutions $(2.5 \mu \mathrm{g} / \mathrm{mL}$ and $5.0 \mu \mathrm{g} / \mathrm{mL})$ as internal standards were prepared in methanol. For the calibration, solutions holding different mixtures of $\mathrm{CBN}$ and $\mathrm{CBN}-\mathrm{d}_{3}$ were prepared (CBN, in the range of $1.0-6.2 \mu \mathrm{g} / \mathrm{mL}$; $\mathrm{CBN}$ $\mathrm{d}_{3}, 2.5 \mu \mathrm{g} / \mathrm{mL}$ ), and for the validation of the HPTLC-ESIMS method, different mixtures of $\mathrm{CBN}$ and $\mathrm{CBN}-\mathrm{d}_{3}$ were used (CBN, 1.4, 1.8, 2.2, 2.5, 3.4, 5.0, $5.4 \mu \mathrm{g} / \mathrm{mL}$; CBN$\left.\mathrm{d}_{3}, 2.5 \mu \mathrm{g} / \mathrm{mL}\right)$.

\section{Detection of CBN with FBS reagent (modified according to an application note from CAMAG [16])}

The post-chromatographic detection reaction was performed with FBS reagent using CBN working solutions and sample extracts ( $25 \mu \mathrm{L}$ aliquots) spotted onto TLC or HPTLC plates. For the preparation of the FBS reagent, FBS $(250 \mathrm{mg})$ was completely dissolved in distilled water $(10 \mathrm{~mL})$ and was mixed with methanol $(25 \mathrm{~mL})$ and dichloromethane $(15 \mathrm{~mL})$. This reagent was always freshly prepared before use. (HP)TLC plates were developed in $n$-hexane/acetone/ triethylamine (40:20:2 v/v/v; see Watanabe et al. [17]), sprayed with the reagent, and the presence of red spots indicated a positive response.

\section{Detection of CBN with cerium-molybdenum reagent}

In addition, post-chromatographic detection reactions were performed with cerium-molybdenum reagent using CBN working solutions and sample extracts ( $25 \mu \mathrm{L}$ aliquots $)$ spotted onto (HP)TLC plates. For the preparation of the ceriummolybdenum reagent, cerium(IV) sulfate (400 mg) and ammonium molybdate (20 g) were dissolved in $10 \%$ (v/v) sulfuric acid $(400 \mathrm{~mL})$. (HP)TLC plates were developed in $n$-heptane/diethyl ether/formic acid (75:25:0.3 v/v/v; according to an application note from CAMAG [16]), n-heptane/diethyl ether $(90: 10 \mathrm{v} / \mathrm{v})$, or $n$-hexane/acetone/triethylamine (40:20:2 v/v/v), sprayed with the reagent, and blue spots became visible after exposure to heat. 


\section{Samples}

Samples of a $3.55-\mathrm{m}$-long sediment core from Badanital $\left(30^{\circ}\right.$ $29^{\prime} 50^{\prime \prime} \mathrm{N}, 78^{\circ} 55^{\prime} 26 \mathrm{E}, 2083 \mathrm{~m}$ a.s.l.), a small lake in the West Himalayan oak forest zone in Northern India, have been investigated. The core was retrieved using a piston corer in January 2008 (see Kotlia and Joshi [18]). Contiguous subsamples were taken in $1 \mathrm{~cm}$ slices and dried at $30{ }^{\circ} \mathrm{C}$ for storage and transportation to the pollen laboratory at the Institute of Geological Sciences, Freie Universität Berlin. Sediment samples, covering a period from $2220 \mathrm{BCE}$ to $1390 \mathrm{CE}$, were examined concerning Cannabis pollen; they were categorized into real samples (positive samples), containing Cannabis pollen, and negative samples without Cannabis pollen. The procedure for pollen analyses is based on morphological characteristics as well as further results of the determination of palynomorphs; detailed results from accelerator mass spectrometry (AMS) radiocarbon dating using bulk sediment rich in organics were described by Demske et al. [15]. For the reconstruction of climatic changes based on geochemical parameters of sediment samples from Badanital lake, see Kotlia and Joshi [18].

\section{HPTLC-ESI-MS analysis}

Standard solutions and the extracts were spotted onto the TLC or HPTLC plates as $2 \mathrm{~mm}$ bands, in $25 \mu \mathrm{L}$ aliquots, $20 \mathrm{~mm}$ from the bottom edge and $8 \mathrm{~mm}$ apart using a Linomat 5 (CAMAG, Switzerland). Plates were developed in a rectangular TLC developing chamber to a distance of $50 \mathrm{~mm}$ in $15 \mathrm{~min}$ using $n$-heptane/diethyl ether $(90: 10 \mathrm{v} / \mathrm{v})$ as the developing solvent. For the optimization of the chromatographic separation, TLC and HPTLC plates as well as various developing solvents were tested, e.g., $n$-heptane/diethyl ether/formic acid $(75: 25: 0.3 \mathrm{v} / \mathrm{v} / \mathrm{v})$ or $n$-hexane/acetone/triethylamine $(40: 20: 2 \mathrm{v} / \mathrm{v} / \mathrm{v})$.

HPTLC plates were inspected both under white light and with under UV light at $\lambda=254 \mathrm{~nm}$. Beside investigations by MS, different spray reagents were also used for the detection of CBN (see detection of CBN with FBS and ceriummolybdenum reagent).

A TLC-MS interface (Plate Express from Advion combined with an isocratic pump) was utilized for the elution of compounds from the HPTLC plates into an expression ${ }^{\mathrm{L}} \mathrm{CMS}$ (compact mass spectrometer from Advion, UK) system, equipped with an ESI ion source (negative mode, capillary temperature $250{ }^{\circ} \mathrm{C}$, capillary voltage $180 \mathrm{~V}$, source voltage offset 20 , source voltage span 30 , ESI source voltage $2500 \mathrm{~V}$, source gas temperature $200^{\circ} \mathrm{C}$, MS scan range $200-400 \mathrm{~m} / \mathrm{z}$ ). Prior to the measurements, substance-specific parameters were determined by direct inlet of CBN working solutions. Methanol was used as eluent (flow rate $0.2 \mathrm{~mL} / \mathrm{min}$ ).

\section{Offline HPTLC-ESI-HRMS analysis}

Standard solutions were spotted onto HPTLC plates; HPTLC plates were developed in $n$-heptane/diethyl ether $(90: 10 \mathrm{v} / \mathrm{v})$, and after $5 \mathrm{~h}$, spots were marked; stationary phase was scraped from the plates and compounds were eluted with methanol $(1 \mathrm{~mL})$. This solution was filtered $(0.2 \mu \mathrm{m}$ PTFE) and utilized for HRMS experiments using a Q Exactive Plus mass spectrometer from Thermo Scientific equipped with an ESI ion source (negative mode, spray voltage $3287 \mathrm{~V}$, spray current $1 \mu \mathrm{A}$, capillary temperature $320^{\circ} \mathrm{C}$, sheath gas flow rate $10 \mathrm{~L} /$ min, MS scan range $200-900 \mathrm{~m} / \mathrm{z}$ ).

\section{Sample extraction and preparation}

The remaining sediment samples analyzed for pollen were sent to the Department of Organic Chemistry, MartinLuther-University Halle-Wittenberg (Halle), and used in the current study. An aliquot $(1 \mathrm{~g})$ of each sample was extracted with methanol/hexane $(10 \mathrm{~mL}, 9: 1 \mathrm{v} / \mathrm{v})$ by the following procedure: $1 \mathrm{~min}$ on a vortex and $15 \mathrm{~min}$ ultrasonic bath at $30^{\circ} \mathrm{C}$ including vortex again after 5 and $10 \mathrm{~min}$. Subsequently, the suspension was centrifuged ( $\left.10 \mathrm{~min}, 2{ }^{\circ} \mathrm{C}, 4200 \mathrm{rpm}\right)$ in a centrifuge 5403 from Eppendorf. The extraction of the sample was repeated five times. The supernatants were combined, and the solution was evaporated to dryness on a rotary evaporator (temperature of the water bath, $30^{\circ} \mathrm{C}$ ). The residue was dissolved in $n$-heptane/diethyl ether $(1 \mathrm{~mL}, 75: 25 \mathrm{v} / \mathrm{v})$ with the help of an ultrasonic bath at $30{ }^{\circ} \mathrm{C}$ for a few seconds. Afterwards, the sample extract was transferred to a Chromabond $\mathrm{SiOH}$ column conditioned with $n$-heptane/ diethyl ether $(75: 25 \mathrm{v} / \mathrm{v})$, the sample container was rinsed with $n$-heptane/diethyl ether $(3 \times 1 \mathrm{~mL}, 75: 25 \mathrm{v} / \mathrm{v})$, the rinse solution was also transferred onto the sorbent, and the analyte was eluted with $n$-heptane/diethyl ether $(2 \mathrm{~mL}, 75: 25 \mathrm{v} / \mathrm{v})$. The eluate (fraction 1: combined solutions, approximately $6 \mathrm{~mL}$ ) was evaporated to dryness on a rotary evaporator (temperature of the water bath, $30{ }^{\circ} \mathrm{C}$ ), and the residue was dissolved in acetonitrile/water $(500 \mu \mathrm{L}, 70: 30 \mathrm{v} / \mathrm{v})$. The solution was transferred to a Chromabond $\mathrm{C}_{18}$ ec column conditioned with acetonitrile/water $(70: 30 \mathrm{v} / \mathrm{v})$. The sample vessel was rinsed with acetonitrile/water $(1 \mathrm{~mL}, 70: 30 \mathrm{v} / \mathrm{v})$, the rinse solution was also transferred onto the sorbent, and the analyte was eluted with acetonitrile/water $(500 \mu \mathrm{L}, 70: 30 \mathrm{v} / \mathrm{v}$, and $3 \mathrm{~mL}$, 80:20 v/v). The eluate (fraction 2: combined solutions, approximately $5 \mathrm{~mL}$ ) was evaporated to dryness on a rotary evaporator (temperature of the water bath, $50{ }^{\circ} \mathrm{C}$ ). The residue was dissolved in methanol $(1 \mathrm{~mL})$ and transferred to a vial. The sample pot was rinsed with methanol $(3 \mathrm{~mL})$, and this solution was also transferred to this vial step-by-step. The sample solution in the vial was concentrated to dryness in a stream of argon with heat from a laboratory sand bath at $70^{\circ} \mathrm{C}$. The residue was solved in methanol $(100 \mu \mathrm{L})$, and a defined 
volume $(25 \mu \mathrm{L})$ of the sample extract was spotted onto a HPTLC plate (Fig. 2).

For the optimization of the extraction procedure, various extraction times and further extracting agents were tested, e.g., dichloromethane/methanol $(90: 10 \mathrm{v} / \mathrm{v}$ and $1: 1 \mathrm{v} / \mathrm{v})$.

\section{Determination of sediment $\mathrm{pH}$}

For the determination of the $\mathrm{pH}$ of a sample, a $\mathrm{pH}$ electrode from HANNA instruments was used. An aliquot $(0.5 \mathrm{~g})$ of the sediment sample was suspended in a solution of calcium chloride $(0.01 \mathrm{M})$ at the ratio of $1: 2.5$. After the sedimentation, the $\mathrm{pH}$ was measured.

\section{Determination of the loss on ignition (modified according to Heiri et al. [19])}

The loss on ignition at $550{ }^{\circ} \mathrm{C}\left(\mathrm{LOI}_{550}\right)$ was determined using a thermobalance STA 449C from Netzsch (reference: empty crucible of corundum). An aliquot of the sample (15-25 mg) was weighted in a crucible of corundum, and a stream of gas $\left(\mathrm{N}_{2} / \mathrm{O}_{2}=80 / 20,50 \mathrm{~mL} / \mathrm{min}\right)$ was applied. Before each measurement, an equilibration of the thermobalance was performed for about $30 \mathrm{~min}$ at room temperature with current gas flow. Afterwards, the sample chamber was heated to $800{ }^{\circ} \mathrm{C}$ (heat rate $10 \mathrm{~K} / \mathrm{min}$ ). The weight loss is proportional to the amount of organic
Fig. 2 Flow diagram for the extraction of the samples and cleanup protocol. For the quantification of the $\mathrm{CBN}$ content, internal standard $\mathrm{CBN}-\mathrm{d}_{3}$ was added after sample has been weighed. For the determination of the recovery, CBN-spiked sediment samples (approximately 140, 250, and $330 \mathrm{ng} \mathrm{CBN/g}$ sediment) were used, and the residue of the purification with reversed-phase sorbent was solved in a methanolic solution of $\mathrm{CBN}^{-d_{3}}(100 \mu \mathrm{L}, 2.5 \mu \mathrm{g} / \mathrm{mL})$ after having been transferred to a vial and before spotting the solution onto a HPTLC plate

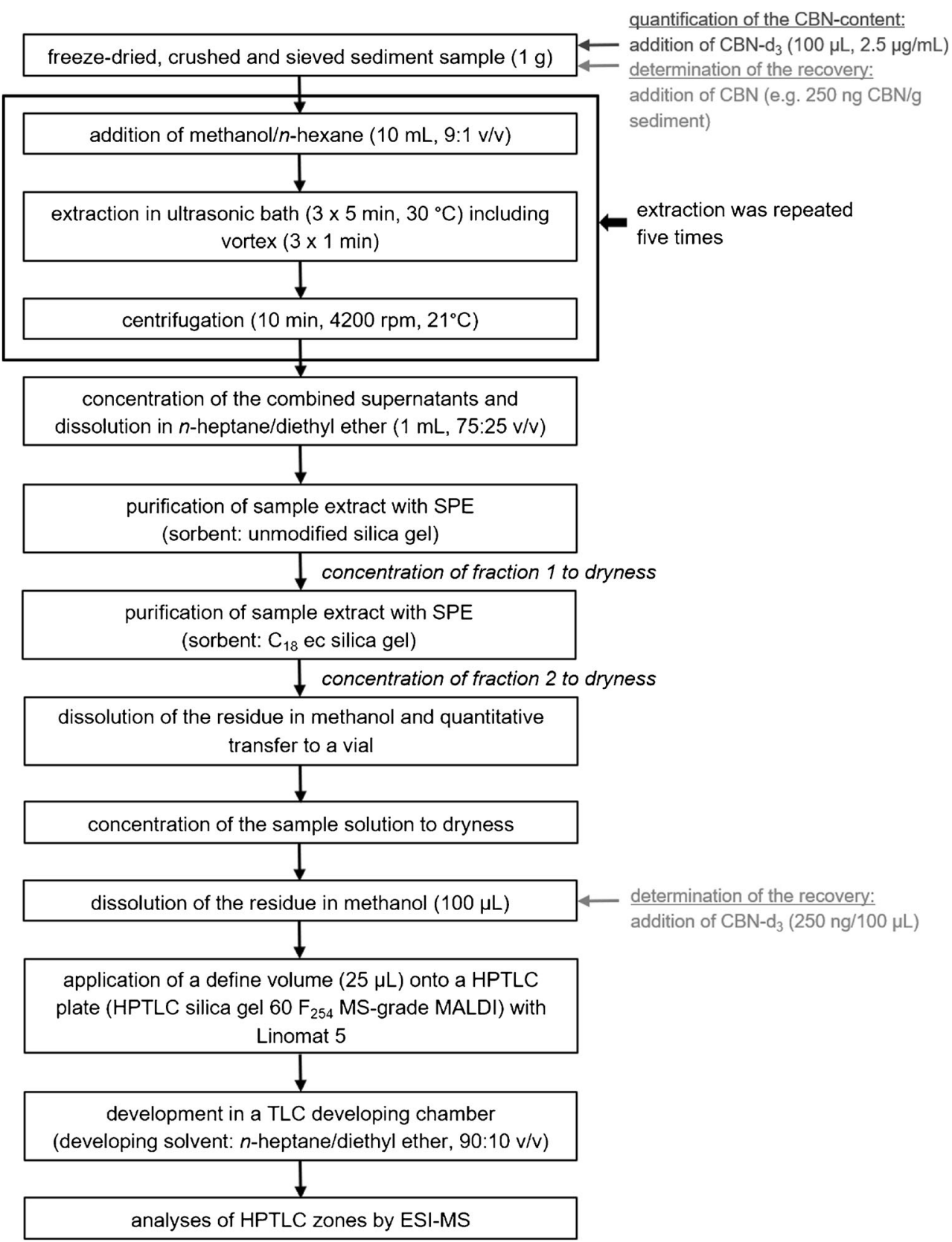


carbon contained in samples. For the calculation, the following formula (1) was used:

$$
L O I_{550}=\left(\left(D W_{105}-D W_{550}\right) / D W_{105}\right) \times 100
$$

where $\mathrm{LOI}_{550}$ represents the LOI at $550{ }^{\circ} \mathrm{C}$ (as percentage), $\mathrm{DW}_{105}$ correspond to the dry weight of the sample before combustion, and $\mathrm{DW}_{550}$ to the dry weight of sample after heating to $550{ }^{\circ} \mathrm{C}$ (both in $\mathrm{mg}$, see Heiri et al. [19]).

\section{Determination of $\mathrm{C} / \mathrm{N}$ content}

The determination of the $\mathrm{C}$ and $\mathrm{N}$ content of the samples were performed with the analytical instrument "Vario EL" from the company Elementar.

\section{Validation of the HPTLC-ESI-MS method}

\section{Specificity}

The test for specificity was performed with a negative sample (without $\mathrm{CBN}$ ) and a real sample (containing $\mathrm{CBN}$ ) applying the post-chromatographic detection reaction with ceriummolybdenum reagent and HPTLC-ESI-MS using standard compounds. For HPTLC-ESI-MS experiments as well as for the detection of $\mathrm{CBN}$ with the cerium-molybdenum reagent, a sample extract was spotted onto a HPTLC plate; the HPTLC plate was developed in $n$-heptane/diethyl ether $(90: 10 \mathrm{v} / \mathrm{v})$ and investigated by HPTLC-ESI-MS or sprayed with ceriummolybdenum reagent.

\section{Linearity, limit of detection, and limit of quantification}

The linearity of the calibration function was tested with the Mandel's test. Limit of detection (LOD) and limit of quantification (LOQ) were determined by means of a calibration curve method according to DIN 32645 [20], thereby spotting the calibration solutions (see preparation of standard solutions) onto HPTLC plates; the HPTLC plates were developed using $n$-heptane/diethyl ether $(90: 10 \mathrm{v} / \mathrm{v})$ and investigated by HPTLC-ESI-MS. Each calibration solution was measured three times, and analyses were executed with average peak areas of the mass peaks of CBN (sum of $\mathrm{m} / \mathrm{z}, 309$ and 354) and $\mathrm{CBN}-\mathrm{d}_{3}$ (sum of $\mathrm{m} / \mathrm{z} 312$ and 357). Average peak area ratios and CBN concentrations are depicted in Fig. S1 and Tab. S1 (see Electronic Supplementary Material, ESM).

\section{Precision}

For determining the repeatability, two to five replicate determinations on eight different days were carried out. For this purpose, a solution containing $\mathrm{CBN}$ and $\mathrm{CBN}-\mathrm{d}_{3}(\mathrm{CBN}$
$3.4 \mu \mathrm{g} / \mathrm{mL}, \mathrm{CBN}-\mathrm{d}_{3} 2.5 \mu \mathrm{g} / \mathrm{mL}$ ) was spotted onto HPTLC plates; HPTLC plates were developed using $n$-heptane/diethyl ether $(90: 10 \mathrm{v} / \mathrm{v})$ and investigated by HPTLC-ESI-MS. For the interpretation of the repeatability, the relative standard deviation (RSD) of the CBN content was used. Furthermore, Dixon's Q test and Neumann trend test were applied for the identification of outliers or trends (see Table S2 of the ESM).

For determining the method precision, sediment sample BT-78 was utilized. Analyses were carried out with a number of six replicates and each aliquot of the sediment sample (approximately $1 \mathrm{~g}$ ) was spiked with a defined concentration of CBN $(100 \mu \mathrm{L} ; 3.4 \mu \mathrm{g} / \mathrm{mL})$ and $\mathrm{CBN}-\mathrm{d}_{3}(100 \mu \mathrm{L} ; 2.5 \mu \mathrm{g} / \mathrm{mL})$. Extractions and preparations of the different samples were performed independently of each other as described above. After SPE using a Chromabond $\mathrm{C}_{18}$ ec column, the residues were dissolved in methanol $(100 \mu \mathrm{L})$ and defined volumes $(25 \mu \mathrm{L})$ of the sample extracts were spotted onto HPTLC plates; HPTLC plates were developed in $n$-heptane/diethyl ether $(90: 10 \mathrm{v} / \mathrm{v})$ and were investigated by HPTLC-ESI-MS. For the interpretation of the method precision, the relative standard deviation (RSD) of the CBN content was used. Furthermore, Dixon's Q test and Neumann trend test were applied for the identification of outliers or trends (see Table S2 of the ESM).

\section{Trueness}

The trueness was expressed in terms of recovery and bias. Bias calculation was performed for two concentration levels with a number of three replicates at each concentration (see Table S3 of the ESM). Sediment samples (approximately $1 \mathrm{~g}$ ) were spiked with a defined concentration of CBN $(100 \mu \mathrm{L}$; $5.4 \mu \mathrm{g} / \mathrm{mL}$ and $1.8 \mu \mathrm{g} / \mathrm{mL})$ and $\mathrm{CBN}^{-} \mathrm{d}_{3}(100 \mu \mathrm{L} ; 2.5 \mu \mathrm{g} / \mathrm{mL})$. Extractions and preparations of the different samples as well as the planar chromatographic separations were performed independently of each other as described above. Real samples were used for bias calculation due to a limited sample amount. For the bias calculation, the following formula (2) was used:

$\widehat{\delta}=\bar{x}-T$

where $\widehat{\delta}$ represents the bias and $T$ correspond to the "true" concentration and $\bar{x}$ to the mean value of the determined concentrations of the spiked sample materials.

\section{Recovery}

Three negative samples from different positions in the sedimentary core were used for the determination of the recovery. After the sediment samples have been weighed (approximately $1 \mathrm{~g}$, see Fig. 2), defined concentrations of CBN $(100 \mu \mathrm{L} ; 1.4,2.5$, and $3.4 \mu \mathrm{g} / \mathrm{mL})$ were added and each concentration level was analyzed in duplicate (see Table S4 of 
the ESM). Extractions and preparations of the different samples were performed independently of each other on different days as described above. After SPE using a Chromabond $\mathrm{C}_{18}$ ec column, the residues were dissolved in a methanolic solution of CBN-d $\mathrm{d}_{3}(100 \mu \mathrm{L} ; 2.5 \mu \mathrm{g} / \mathrm{mL})$ and were spotted onto HPTLC plates; HPTLC plates were developed in $n$-heptane/ diethyl ether $(90: 10 \mathrm{v} / \mathrm{v})$ and were investigated by HPTLCESI-MS. The calculated CBN contents were compared with the target concentrations and the recovery rate was determined.

\section{Stability of the standards}

For testing the storage stability of standard solutions, solutions of CBN $(50$ and $100 \mu \mathrm{g} / \mathrm{mL})$ were stored at $-12{ }^{\circ} \mathrm{C}$ in the dark, at room temperature (average temperature $+28{ }^{\circ} \mathrm{C}$ ) in the dark and at room temperature exposed to sunlight. The different solutions were examined over a 4-week period. For analyses, solutions of $\mathrm{CBN}$ were diluted, $\mathrm{CBN}-\mathrm{d}_{3}$ was added, and the mixtures (CBN 2.2 and $5.0 \mu \mathrm{g} / \mathrm{mL} ; \mathrm{CBN}^{-\mathrm{d}_{3}} 2.5 \mu \mathrm{g} /$ $\mathrm{mL}$ ) were spotted onto HPTLC plates. Mass peak areas of CBN (sum of $\mathrm{m} / \mathrm{z}, 309$ and 354) and $\mathrm{CBN}^{-\mathrm{d}_{3}}$ (sum of $\mathrm{m} / \mathrm{z}$ 312 and 357) were utilized for calculating the stability of CBN. For the identification of trends, a trend test by Neumann [20] was performed (see Table S5 of the ESM).

In addition, the stability of $\mathrm{CBN}$ and $\mathrm{CBN}-\mathrm{d}_{3}$ already having been spotted onto (HP)TLC plates was evaluated. For this purpose, a solution containing $\mathrm{CBN}$ and $\mathrm{CBN}-\mathrm{d}_{3}(\mathrm{CBN}$ $5.0 \mu \mathrm{g} / \mathrm{mL} ; \mathrm{CBN}-\mathrm{d}_{3} 5.0 \mu \mathrm{g} / \mathrm{mL}$ ) was spotted in triplicate onto a TLC and a HPTLC plate. (HP)TLC plates were developed in $n$-heptane/diethyl ether $(90: 10 \mathrm{v} / \mathrm{v})$ and were investigated by HPTLC-ESI-MS at a time interval of $3 \mathrm{~h}$ (measuring after 0.5, 1.5 , and $3 \mathrm{~h}$ ). Furthermore, investigations were performed on (HP)TLC plates spotted with CBN and $\mathrm{CBN}-\mathrm{d}_{3}$ without developing the chromatograms. For analyses, mass peak intensities of CBN (ratios of $m / z 309$ and 354) and CBN-d (ratios $^{2}$ of $\mathrm{m} / \mathrm{z}, 312$ and 357) were utilized.

\section{Results and discussion}

\section{Development of a HPTLC-ESI-MS method for the identification and quantification of CBN in sediment samples}

Determination of CBN content in sediment samples was performed by HPTLC-ESI-MS. For this purpose, sediment samples were extracted followed by a subsequent elimination of disturbing matrix compounds using an orthogonal SPE sample preparation. Afterwards, purified extracts were spotted onto HPTLC plates, the HPTLC plates were developed and the HPTLC zones were analyzed by ESI-MS (MS scan range $m / z, 200-400)$. Mass spectra of standards eluted from HPTLC silica gel 60 plates show intense peaks at $\mathrm{m} / z 309$ and 312, assigned to the quasi-molecular ions $[\mathrm{M}-\mathrm{H}]^{-}$of $\mathrm{CBN}$ and CBN- $\mathrm{d}_{3}$. In addition, extra mass peaks at $m / z 354$ (working solutions of CBN spotted onto HPTLC plates) and 357 (working solutions of $\mathrm{CBN}-\mathrm{d}_{3}$ spotted onto HPTLC plates) were observed (Fig. 3). These signals appear after the application of CBN and $\mathrm{CBN}-\mathrm{d}_{3}$ onto TLC or HPTLC silica gel 60 plates and were not found in fresh or aged (for $24 \mathrm{~h}$ ) methanolic working solutions of $\mathrm{CBN}$ and $\mathrm{CBN}-\mathrm{d}_{3}$ or in the context of blanks (blanks for the whole method as well as investigations on TLC or HPTLC plates using different developing solvents without the addition of $\mathrm{CBN}$ or $\mathrm{CBN}-\mathrm{d}_{3}$ ). However, after development of the (HP)TLC plates, the proportion of these extra peaks increased compared with investigations without contact to a developing solvent. In this context, different developing solvents and stationary phases (octadecyl-modified TLC silica layers, unmodified (HP)TLC silica layers with and without fluorescent indicator on aluminum sheets and glass plates) were tested. Mass spectra of standards eluted from octadecyl-modified TLC silica layers show peaks at $m / z, 309$ and 312. However, no signals at $\mathrm{m} / z, 354$ or 357 were observed. In contrast, in all experiments performed on unmodified silica layers, extra mass peaks at $\mathrm{m} / \mathrm{z} 354$ and 357 were detected. Furthermore, the proportion of these peaks increased in time. Immediately after application of the cannabinoids and the development of the HPTLC silica gel 60 plates, peak intensity ratios of $m / z 309 / 354$ and 312/357 were 10.1 (8.01E7/
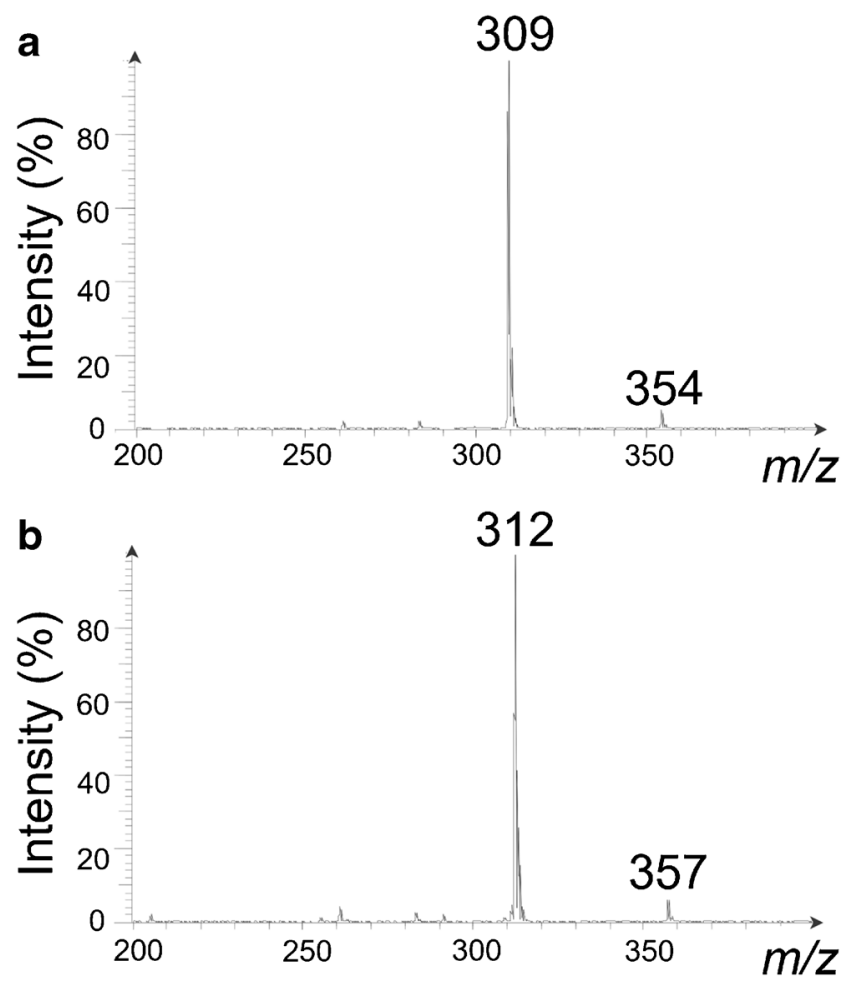

Fig. 3 MS spectrum of a $\mathrm{CBN}$ and $\mathbf{b} \mathrm{CBN}-\mathrm{d}_{3}$ spotted onto a HPTLC silica gel 60 plate recorded immediately after chromatographic separation using $n$-heptane/diethyl ether (90:10 v/v) as developing solvent 
7.91E6) and 8.3 (3.65E7/4.41E6, see Fig. S2a of the ESM). After $3 \mathrm{~h}$, the ratios were in either case $0.3(1.67 \mathrm{E} 7 / 5.08 \mathrm{E} 7$ and 7.62E6/2.61E7, see Fig. S2b of the ESM). Thus, investigations were performed immediately after application and chromatographic separation and signals at $\mathrm{m} / \mathrm{z}, 354$ and 357 were included in the quantitative determination of $\mathrm{CBN}$.

Furthermore, methanolic working solutions of CBD and CBD- $\mathrm{d}_{3}$ were spotted onto TLC or HPTLC silica gel 60 plates. After the development of the plates, besides intense peaks at $m / z, 313$ and 316 (assigned to the quasi-molecular ions $[\mathrm{M}-\mathrm{H}]^{-}$), extra peaks with a mass shift of 45 were also detected at $\mathrm{m} / z, 358$ and 361 (see Fig. S3a and S3b of the ESM). As indicated by TLC and HRMS studies on CBN and $\mathrm{CBN}-\mathrm{d}_{3}$, the mass shift of 45 points to the presence of transient adducts with the silica gel from the plates. This will be subject to further studies.

In addition, different spray reagents were tested to find a pretest confirming the presence of $\mathrm{CBN}$ in sediment samples by a color reaction.

\section{Optimization of mobile and stationary phase for planar chromatography}

For the optimization of the planar chromatographic separation, different sorbents and solvents were tested. An acceptable separation of $\mathrm{CBN}$ and matrix compounds was found on TLC silica gel 60 sorbent using $n$-heptane/diethyl ether/formic acid $(75: 25: 0.3 \mathrm{v} / \mathrm{v} / \mathrm{v})$ or $n$-hexane/acetone/triethylamine $(40: 20: 2 \mathrm{v} / \mathrm{v} / \mathrm{v})$ as developing solvent (see Fig. S4 of the ESM). However, bands were rather diffused. Therefore, normal phase HPTLC on silica gel 60 was used to achieve sharper bands, thereby obtaining a satisfactory resolution of $\mathrm{CBN}$ and matrix compounds using $n$-heptane/diethyl ether $(90: 10 \mathrm{v} / \mathrm{v})$ as the mobile phase.

\section{Optimization of sample extraction and preparation}

Different extracting agents and extraction times were tested using analytical sea sand spiked with $\mathrm{CBN}$ due to a limited sample amount (Table 1). An extraction in an ultrasonic bath with methanol $/ n$-hexane $(90: 10 \mathrm{v} / \mathrm{v})$ for $5 \times 15 \mathrm{~min}$ provided satisfactory results concerning the recovery of CBN (recovery rate $97 \%$ ). Sample handling was also optimized with $\mathrm{CBN}$ spiked sea sand samples.

Table 1 Optimization of sample extraction using different extracting agents and analytical sea sand spiked with CBN (extraction time $5 \times$ $15 \mathrm{~min})$

\begin{tabular}{ll}
\hline Extracting agent & Recovery $(\%)$ \\
\hline Methanol $/ n$-hexane $(90: 10 \mathrm{v} / \mathrm{v})$ & 97 \\
Dichloromethane/methanol $(90: 10 \mathrm{v} / \mathrm{v})$ & 90 \\
\hline
\end{tabular}

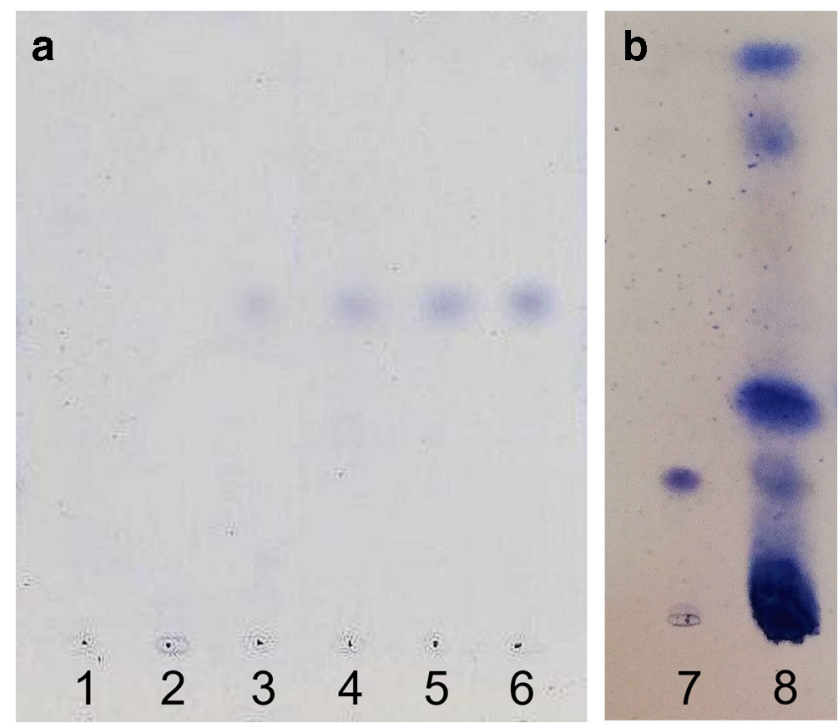

Fig. 4 HPTLC silica gel 60 plates developed using a $n$-heptane/diethyl ether/formic acid (75:25:0.3 v/v/v) or $\mathbf{b} n$-heptane/diethyl ether $(90: 10 \mathrm{v} /$ v) as developing solvent after derivatization with cerium-molybdenum reagent; observed under white light. Tracks $1-7=\mathrm{CBN}$ standard (from left to right increasing $\mathrm{CBN}$ concentration: 7.5, 15, 25, 55, 85, 125, 190 ng CBN/HPTLC zone); 8 = extract (extracting agent: methanol/ hexane $(10 \mathrm{~mL}, 9: 1 \mathrm{v} / \mathrm{v}))$ of real sample BT-96 spiked with $\mathrm{CBN}-\mathrm{d}_{3}$ (62.5 ng CBN-d $\mathrm{d}_{3} / \mathrm{HPTLC}$ zone)

For the determination of CBN in sediment matrices (extracts of real and spiked negative samples), two SPE columns were combined. Matrix simplification was carried out with a combination of normal phase and reversed phase sorbents. Some losses of $\mathrm{CBN}$ during this two-step purification procedure were eliminated through fine-tuning (recovery rate of

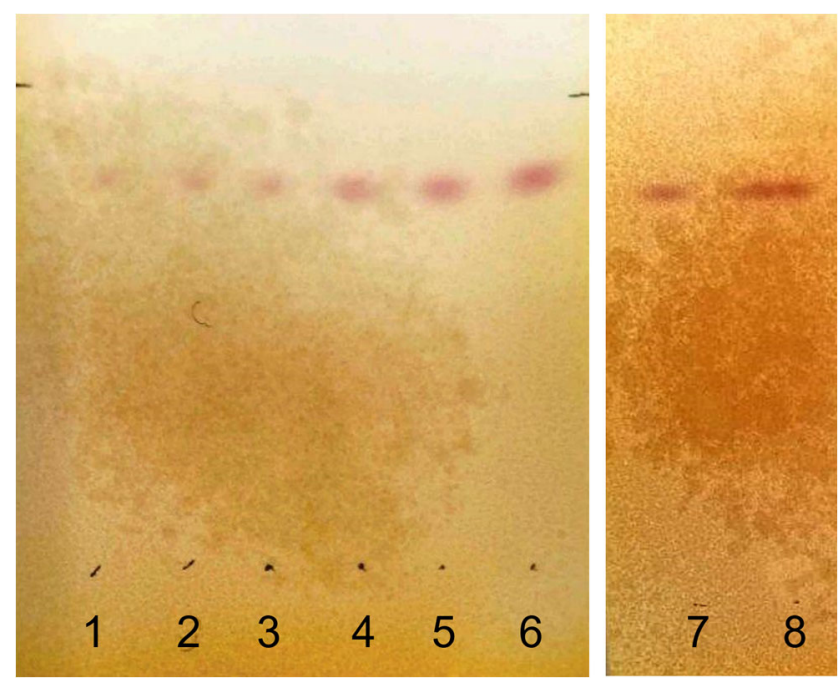

Fig. 5 HPTLC silica gel 60 plates developed using $n$-hexane/acetone/ triethylamine $(40: 20: 2 \mathrm{v} / \mathrm{v} / \mathrm{v})$ as developing solvent after derivatization with FBS reagent; observed under white light. Tracks $1-7=\mathrm{CBN}$ standard (from left to right increasing $\mathrm{CBN}$ concentration: 7.5, 15, 25, 55, 85, 125, $190 \mathrm{ng}$ CBN/HPTLC zone); $8=$ extract (extracting agent: methanol/hexane $(10 \mathrm{~mL}, 9: 1 \mathrm{v} / \mathrm{v}))$ of real sample BT-96 spiked with CBN-d ${ }_{3}\left(62.5\right.$ ng CBN-d d $_{3}$ HPTLC zone) 
Table 2 Chromatographic data for CBN and observed colors of the bands using different spray reagents

\begin{tabular}{llllll}
\hline Developing solvent & \multicolumn{2}{l}{$\mathrm{R}_{\mathrm{F}}$ value } & & Band color \\
\cline { 2 - 3 } & TLC plate & HPTLC plate & & $\begin{array}{l}\text { Cerium-molybdenum } \\
\text { reagent }\end{array}$ \\
\hline$n$-Heptane/diethyl ether/formic acid $(75: 25: 0.3 \mathrm{v} / \mathrm{v} / \mathrm{v})$ & 0.4 & & Blue & None \\
$n$-Heptane/diethyl ether $(90: 10 \mathrm{v} / \mathrm{v})$ & - & 0.5 & & Red \\
$n$-Hexane/acetone/triethylamine $(40: 20: 2 \mathrm{v} / \mathrm{v} / \mathrm{v})$ & 0.6 & 0.8 & & \\
\hline
\end{tabular}

CBN for the whole procedure including extraction and purification: see validation results).

\section{Detection of CBN by spray reagents}

Different spray reagents were tested to confirm the presence of CBN in the sediment samples. The ceriummolybdenum reagent is suitable for the detection of low CBN concentrations up to $25.0 \mathrm{ng} \mathrm{CBN} / \mathrm{HPTLC}$ zone using $n$-heptane/diethyl ether/formic acid (75:25:0.3 v/v/ v, Fig. 4), $n$-heptane/diethyl ether $(90: 10 \mathrm{v} / \mathrm{v})$, or $n$-hexane/acetone/triethylamine $(40: 20: 2 \mathrm{v} / \mathrm{v} / \mathrm{v})$. CBN concentrations up to $7.5 \mathrm{ng}$ CBN/HPTLC zone were detectable with the FBS reagent using $n$-hexane/acetone/ triethylamine (40:20:2 v/v/v, Fig. 5). In the presence of the examined sediment matrices, exclusively $\mathrm{CBN}$ reacts under the described conditions with FBS resulting in red bands (FBS is known as a selective detection reagent for cannabinoids, see Fischedick et al. [21-23]). Thus, a postchromatographic detection with FBS reagent was found to be appropriate as a pretest to confirm the presence of low CBN concentrations in sediment samples.
$\mathrm{R}_{\mathrm{F}}$ values of CBN obtained by developing TLC or HPTLC plates in $n$-heptane/diethyl ether/formic acid $(75: 25: 0.3 \mathrm{v} / \mathrm{v} / \mathrm{v})$, $n$-heptane/diethyl ether $(90: 10 \mathrm{v} / \mathrm{v})$, and $n$-hexane/acetone/ triethylamine $(40: 20: 2 \mathrm{v} / \mathrm{v} / \mathrm{v})$ as well as observed colors of the bands are summarized in Table 2 .

\section{Validation results of HPTLC-ESI-MS method}

Linearity, LOD, and LOQ were evaluated for CBN after chromatographic separation. The results from validation are summarized in Table 3 (further data see Table S1 and Fig. S1 of the ESM). LOD and LOQ were considered adequate for the purposes of the present study.

The developed HPTLC-ESI-MS method is specific for the determination of $\mathrm{CBN}$ in sediment samples. Postchromatographic detection reaction with cerium-molybdenum reagent as well as the HPTLC-ESI-MS analyses on negative samples and real samples showed that $\mathrm{CBN}$ can be qualified and quantified even in the presence of interfering matrix components. Other related compounds being present in the complex sediment samples did not interfere with CBN during HPTLCESI-MS analyses. The method precision and the repeatability were determined with a RSD of $4.1 \%$ and $4.3 \%$ (see Table S2
Table 3 Linearity, LOD, and LOQ for CBN determination by HPTLC-ESI-MS (tv, test value; $\mathrm{cv}$, characteristic value)

\begin{tabular}{ll}
\hline Key figures & Results \\
\hline Range (ng CBN/HPTLC zone) & $25-155$ \\
$r^{2}$ (coefficient of determination) & 0.9979 \\
Sy (residual standard deviation) & 0.034 \\
Sx (standard deviation for the method) & 1.991 \\
Residuals are normally distributed (R/s test, 99\%) & Yes (tv $=3.32 ; \mathrm{cv}=2.86-4.34)$ \\
Residuals show a trend (Neumann trend test, 99\%) & No (tv $=2.73 ; \mathrm{cv}=0.89)$ \\
Equation curve & $\mathrm{y}(\mathrm{x})=0.0172 \mathrm{x}+0.0245$ \\
& $\mathrm{y}: \mathrm{peak}$ area ratio of CBN and CBN-d 3 \\
& $\mathrm{x}: \mathrm{concentration}$ of CBN (ng CBN/ HPTLC zone) \\
LOD (ng CBN/ HPTLC zone) & 6.4 \\
LOQ (ng CBN/ HPTLC zone) & 20.7 \\
Results of the Mandel's test according to DIN 32645 & \\
Optimal regression model & Linear (tv $=0.02 ; \mathrm{cv}=9.64)$ \\
Linear regression acceptable & Yes \\
\hline
\end{tabular}




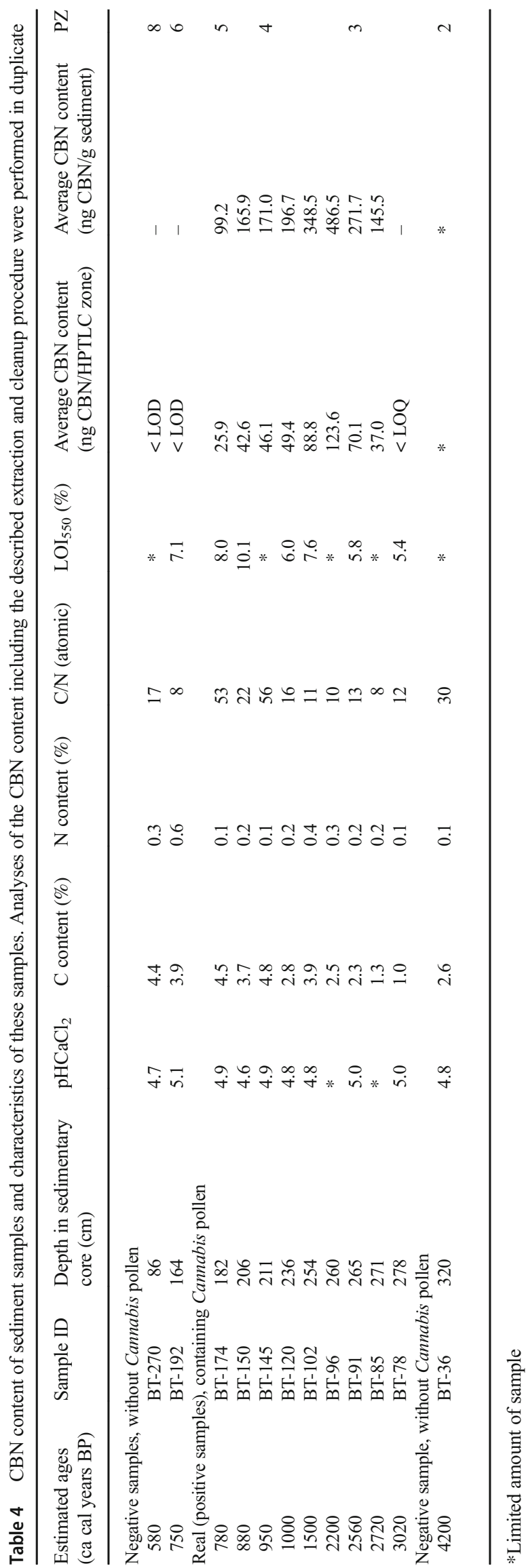

of the ESM), thereby classifying only one measured value as outliner by Dixon's test and was removed from the evaluation. The recovery rate of CBN after sample extraction and the described cleanup procedure (see sample extraction and preparation), determined with spiked negative samples from different positions in the sedimentary core, ranged from 63 to $82 \%$, with an average recovery rate of $73 \%$ (see Table S4 of the ESM). Furthermore, no statistical difference has been observed between the mean and the "true" values (see bias calculation and Table S3 of the ESM). The storage stability of standard CBN solutions $(2.2$ and $5.0 \mu \mathrm{g} / \mathrm{mL}$ ) was evaluated under different conditions (at $-12{ }^{\circ} \mathrm{C}$ in the dark, at room temperature in the dark, and exposed to sunlight). The tests showed that the concentration of CBN did not decrease more than $72 \%$ after 4 weeks (see Fig. S5 of the ESM). However, CBN underwent minor losses, maximal $84 \%$, at a higher concentration of $5.0 \mu \mathrm{g} / \mathrm{mL}$. Furthermore, no trend is discernible using a Neumann trend test.

In addition, it is conceivable to dissolve residues before the application onto HPTLC plates in a smaller volume of solvent (e.g., $30 \mu \mathrm{L}$ instead of $100 \mu \mathrm{L}$ ) for increasing the concentration of the extract. This could enable a characterization of $\mathrm{CBN}$ in very low concentrations.

Thus, the method gives satisfactory results and allowed an appropriate examination of the CBN content in sediment samples.

\section{Analysis of sediment samples}

The quantitative determination of $\mathrm{CBN}$ in sediment samples was performed by HPTLC-ESI-MS. In this context, a series of twelve sediment samples of one core from a small lake in the Garhwal Himalaya, referred to as Badanital lake, was analyzed in duplicate. The results as well as the sample position in the sedimentary core and estimated ages (for age estimation based on radiocarbon dating, see Demske et al. [15]) of the investigated samples are summarized in Table 4. Prior to our investigations, palynological analyses were performed (for characteristics of the respective pollen zones (PZ), see Demske et al. [15]), and Cannabis pollen were proven in the sample material; these samples were categorized as real (positive) samples. In contrast, samples holding no Cannabis pollen were categorized as negative samples. For these negative samples, the absence of CBN was assumed. Postchromatographic detection reactions with FBS as well as HPTLC-ESI-MS studies confirmed the absence of CBN or a CBN content lower than $6.4 \mathrm{ng}$ CBN/HPTLC zone (LOD), i.e., $25.6 \mathrm{ng} \mathrm{CBN} / \mathrm{g}$ sediment.

Furthermore, $\mathrm{C}$ and $\mathrm{N}$ contents were determined to estimate the content of organic matter of the sample material as well as the $\mathrm{C} / \mathrm{N}$ ratios of organic matter. For investigated sediment samples, $\mathrm{C}$ contents correspond approximately to the total organic carbon (TOC) concentration due to $\mathrm{pH}$ values 
Fig. 6 HPTLC chromatogram of (1) CBN standard (190 ng CBN/ HPTLC zone) and (2) an extract of real sample BT-102 spiked with $\mathrm{CBN}-\mathrm{d}_{3}\left(62.5 \mathrm{ng} \mathrm{CBN}-\mathrm{d}_{3} /\right.$ HPTLC zone) as well as a related MS spectrum (HPTLC silica gel 60 plate developed in $n$-heptane/ diethyl ether $(90: 10 \mathrm{v} / \mathrm{v})$; observed with an UV light source at $254 \mathrm{~nm}$; extracting agent: methanol/hexane $(10 \mathrm{~mL}, 9: 1 \mathrm{v} /$ v); after an orthogonal SPE sample preparation)

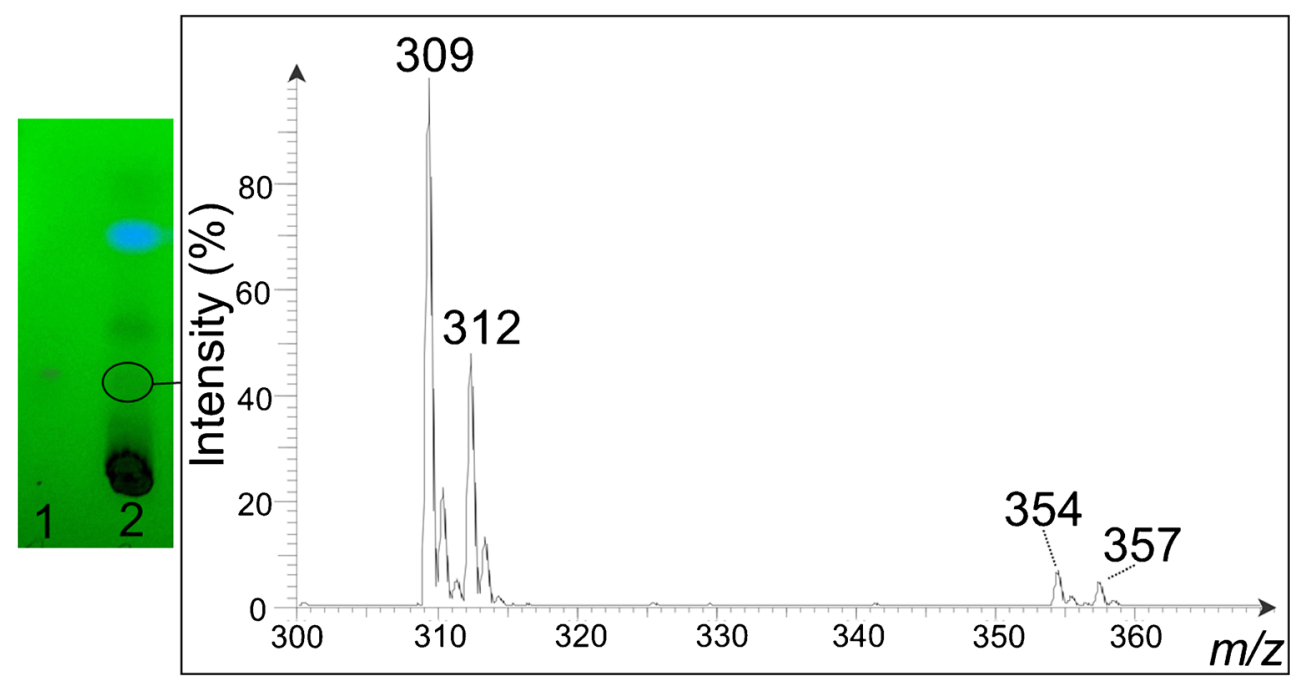

between 4.6 and 5.0 and the resulting absence of carbonate carbon. With $\mathrm{C}$ contents mostly between 3 and 4\%, studied samples were rather rich in organic matter. Measured loss on ignition values at $550{ }^{\circ} \mathrm{C}\left(\mathrm{LOI}_{550}\right)$, as a further parameter for estimating the organic content of the sediment samples (see Heiri et al. [19]), confirmed this finding. C/N ratios of 20 and greater indicating organic matter rather from vascular land plants than from phytoplankton (see Meyers and Teranes [24]) and match with findings of Demske et al. [15] (admixtures of plant fragments and woody material were described). $\mathrm{C} / \mathrm{N}$ values of 8-13 point to organic matter from phytoplankton or a nearly equal mixture of algal and vascular plant contributions. For further geochemical parameters of sediment samples from Badanital lake or discussions concerning past vegetation or climatic changes, see Demske et al. and Kotlia and Joshi $[15,18]$.

The CBN content of the investigated real samples varied between 99.2 and $486.5 \mathrm{ng} \mathrm{CBN/g}$ sediment with a maximum content in PZ 4 at a depth of $260 \mathrm{~cm}$. A characteristic HPTLC chromatogram of an extract and the corresponding MS spectrum is shown in Fig. 6. The data set indicates a correlation with the pollen records of Demske et al. [15]. A high pollen concentration of Cannabis type was also found in PZ 3 (293$262 \mathrm{~cm}$; approximately 1620-480 BC) and $4(262-209 \mathrm{~cm}$; approximately $480 \mathrm{BC}-1050 \mathrm{AD})$, followed by a decreasing contribution of Cannabis type in PZ 5 (209-173 cm; approximately 1050-1160 AD). The high percentages of Cannabis pollen were interpreted as an indicator of water retting of hemp and the confidential interval of intense retting at Badanital was dated from approximately $480 \mathrm{BC}$ to $1050 \mathrm{AD}$. This hypothesis is largely corroborated by the record of sedimentary CBN. However, a systematic analysis of sediment core samples from Badanital lake is needed for a detailed discussion of the CBN content with regard to ancient retting activities. This remains the goal of additional investigations to be performed in the future.

\section{Conclusion}

In this paper, we report on the application of HPTLC-ESI-MS to identify and quantify the cannabinoid $\mathrm{CBN}$, an unequivocal molecular biomarker for the Cannabis species and consequently a tracer for ancient water retting of Cannabis in sediment samples. In the course of method development, planar chromatographic separation, sample extraction, and the subsequent cleanup procedure, using an orthogonal SPE sample preparation, were optimized. To evaluate the potential of this method, parameter such as LOD, LOQ, linearity, recovery rate, method precision, and storage stability were determined. The validated method showed a satisfactory overall analytical performance and determined CBN contents of sediment samples from a small lake in Northern India match very well with pollen records reported in previous studies. In addition, different spray reagents for a post-chromatographic detection of CBN were tested. FBS reagent enables, under the selected conditions, a sensitive and specific detection of $\mathrm{CBN}$ in sediment samples.

In conclusion, HPTLC-ESI-MS is a relatively simple, rapid method enabling a high-throughput and low-cost screening of complex and challenging sediment samples as a natural archive for environmental changes and human activities. Considering the still fragmentary knowledge on ancient retting sites and fact that pollen records reflect the presence of Cannabis, however, not really the retting of Cannabis, this method is a promising approach to track more specifically the retting processes for reconstructing the Cannabis retting history.

Acknowledgments Open Access funding provided by Projekt DEAL. This work was supported by the German Research Foundation (DFG, project number 425225219). The authors are grateful to Maximilian Schneider and Senta Ludwig for the determination of the $\mathrm{C}$ and $\mathrm{N}$ contents and to Oliver Kraft for continuing support in the laboratory (MartinLuther-Universität Halle-Wittenberg). Special thanks are due to Dr. Christian Ihling and Prof. Dr. Andrea Sinz for the HRMS measurements. 


\section{Compliance with ethical standards}

Conflict of interest The authors declare that they have no conflict of interest.

Open Access This article is licensed under a Creative Commons Attribution 4.0 International License, which permits use, sharing, adaptation, distribution and reproduction in any medium or format, as long as you give appropriate credit to the original author(s) and the source, provide a link to the Creative Commons licence, and indicate if changes were made. The images or other third party material in this article are included in the article's Creative Commons licence, unless indicated otherwise in a credit line to the material. If material is not included in the article's Creative Commons licence and your intended use is not permitted by statutory regulation or exceeds the permitted use, you will need to obtain permission directly from the copyright holder. To view a copy of this licence, visit http://creativecommons.org/licenses/by/4.0/.

\section{References}

1. Russo EB. History of cannabis and its preparations in Saga, science, and sobriquet. Chem Biodivers. 2007;4(8):1614-48. https://doi. org/10.1002/cbdv.200790144.

2. Jiang H, Wang L, Merlin MD, Clarke RC, Pan Y, Zhang Y, et al. Ancient Cannabis burial shroud in a central Eurasian cemetery. Econ Bot. 2016;70(3):213-21. https://doi.org/10.1007/s12231016-9351-1.

3. Jiang H-E, Li X, Zhao Y-X, Ferguson DK, Hueber F, Bera S, et al. A new insight into Cannabis sativa (Cannabaceae) utilization from 2500-year-old Yanghai Tombs, Xinjiang, China. J Ethnopharmacol. 2006;108(3):414-22. https://doi.org/10.1016/j.jep.2006.05.034.

4. Andre CM, Hausman J-F, Guerriero G. Cannabis sativa: The Plant of the Thousand and One Molecules. Front Plant Sci. 2016;7:19. https://doi.org/10.3389/fpls.2016.00019.

5. Potter DJ. A review of the cultivation and processing of cannabis (Cannabis sativa L.) for production of prescription medicines in the UK. Drug Test Anal. 2014;6(1-2):31-8. https://doi.org/10.1002/ dta.1531.

6. Pacifici R, Marchei E, Salvatore F, Guandalini L, Busardò Francesco P, Pichini S. Evaluation of cannabinoids concentration and stability in standardized preparations of cannabis tea and cannabis oil by ultra-high performance liquid chromatography tandem mass spectrometry. Clin Chem Lab Med. 2017;55(10):1555-63. https://doi.org/10.1515/cclm-2016-1060.

7. Trofin IG, Vlad C, Dabija G, Filipescu L. Influence of storage conditions on the chemical potency of herbal cannabis. Rev Chim. 2011;62(6):639-45.

8. Trofin IG, Dabija G, Vaireanu D-I, Filipescu L. Long - term storage and cannabis oil stability. Rev Chim. 2012;63(3):293-7.

9. Trofin IG, Dabija G, Vaireanu D-I, Filipescu L. The influence of long-term storage conditions on the stability of cannabinoids derived from cannabis resin. Rev Chim. 2012;63(4):422-7.

10. Harvey DJ. Stability of cannabinoids in dried samples of cannabis dating from around 1896-1905. J Ethnopharmacol. 1990;28(1): 117-28. https://doi.org/10.1016/0378-8741(90)90068-5.
11. Lavrieux M, Jacob J, Disnar J-R, Bréheret J-G, Le Milbeau C, Miras Y, et al. Sedimentary cannabinol tracks the history of hemp retting. Geology. 2013;41(7):751-4. https://doi.org/10.1130/ g34073.1.

12. Citti C, Braghiroli D, Vandelli MA, Cannazza G. Pharmaceutical and biomedical analysis of cannabinoids: a critical review. J Pharm Biomed Anal. 2018;147:565-79. https://doi.org/10.1016/j.jpba. 2017.06.003.

13. Leghissa A, Hildenbrand ZL, Schug KA. A review of methods for the chemical characterization of cannabis natural products. J Sep Sci. 2018;41(1):398-415. https://doi.org/10.1002/jssc.201701003.

14. Vozella V, Zibardi C, Ahmed F, Piomelli D. Fast and sensitive quantification of $\Delta$ (9)-tetrahydrocannabinol and its main oxidative metabolites by liquid chromatography/tandem mass spectrometry. Cannabis Cannabinoid Res. 2019;4(2):110-23. https://doi.org/10. 1089/can.2018.0075.

15. Demske D, Tarasov PE, Leipe C, Kotlia BS, Joshi LM, Long T. Record of vegetation, climate change, human impact and retting of hemp in Garhwal Himalaya (India) during the past 4600 years. Holocene. 2016;26(10):1661-75.

16. Camag. Identification and quantification of different cannabinoids in Cannabis sativa. https://www.camag.com/en/tlc_hptlc/camag laboratory/methods.cfm?ao=-1. 2017. Accessed 3rd April 2019.

17. Watanabe K, Yamaori S, Funahashi T, Kimura T, Yamamoto I. 8Hydroxycannabinol: a new metabolite of cannabinol formed by human hepatic microsomes. Forensic Toxicol. 2006;24(2):80-2. https://doi.org/10.1007/s11419-006-0016-0.

18. Kotlia BS, Joshi LM. Late Holocene climatic changes in Garhwal Himalaya. Curr Sci. 2013;104(7):911-9.

19. Heiri O, Lotter AF, Lemcke G. Loss on ignition as a method for estimating organic and carbonate content in sediments: reproducibility and comparability of results. J Paleolimnol. 2001;25(1):10110. https://doi.org/10.1023/a:1008119611481.

20. Kromidas S. Handbuch Validierung in der Analytik. Weinheim: Wiley-VCH; 2011.

21. Fischedick JT, Glas R, Hazekamp A, Verpoorte R. A qualitative and quantitative HPTLC densitometry method for the analysis of cannabinoids in Cannabis sativa L. Phytochem Anal. 2009;20(5):4216. https://doi.org/10.1002/pca.1143.

22. Hazekamp A, Peltenburg A, Verpoorte R, Giroud C. Chromatographic and spectroscopic data of cannabinoids from Cannabis sativa L. J Liq Chromatogr Relat Technol. $2005 ; 28(15): 2361-82$. https://doi.org/10.1080/ 10826070500187558.

23. Corrigan D, Lynch JJ. An investigation of potential staining reagents for the Glandular Trichomes of Cannabis sativa. Planta Med. 1980;40(S 1):163-9. https://doi.org/10.1055/s-20081075020.

24. Meyers PA, Teranes JL. Sediment organic matter. In: Last WM, Smol JP, editors. Tracking environmental change using lake sediments: physical and geochemical methods. Dordrecht: Springer Netherlands; 2001. p. 239-69.

Publisher's note Springer Nature remains neutral with regard to jurisdictional claims in published maps and institutional affiliations. 